\title{
How Do Physicians Conduct Medication Reviews?
}

\author{
Derjung M. Tarn, MD, $P h D^{7}$, Debora A. Paterniti, PhD ${ }^{2,3}$, Richard L. Kravitz, MD, MSPH , \\ Stephanie Fein, $M D, M P H^{4}$, and Neil S. Wenger, $M D, M P H^{4}$
}

${ }^{1}$ Department of Family Medicine, David Geffen School of Medicine, University of California-Los Angeles, Los Angeles, CA, USA; ${ }^{2}$ Department of Sociology, University of California-Davis, Davis, CA, USA; ${ }^{3}$ Center for Healthcare Policy and Research, University of California-Davis Medical Center, Sacramento, CA, USA; ${ }^{4}$ Division of General Internal Medicine and Health Services Research, David Geffen School of Medicine, University of California-Los Angeles, Los Angeles, CA, USA.

BACKGROUND: Medication reviews are recommended annually for older patients. A medication review is a discussion of a patient's complete set of medications, but the actual content of a review is not well specified. The medical literature suggests that it is an exhaustive evaluation, but what physicians actually ask about their patients' medication regimens has been little studied.

OBJECTIVE: To describe what physicians do when they review medications in the office setting.

METHODS: Qualitative content analysis of audio-taped encounters between 100 patients aged 65 and older and 28 primary care physicians in two health care systems in Sacramento, California.

RESULTS: Physicians use a combination of nonmutually exclusive strategies when reviewing chronic medications that include: (1) efforts to obtain a complete list of patient medications (36\% of visits), (2) discussion of a topic related to the management of each of a patient's chronic medications (47\% of visits), and (3) sequential discussion of the majority of a patient's medications without intervening discussion $(45 \%$ of visits). Of 10 medication management topics that were discussed in medication reviews, a mean of 1.5 topics $(\mathrm{SD}=1.7$, range $0-7)$ were mentioned for each medication, with efficacy and directions being most common. Physicians conducted a sequential discussion that included discussion of each of a patient's medications in only $32 \%$ of visits.

CONCLUSIONS: Comprehensive discussions about chronic medications are uncommon in routine practice. Practical conceptualization of what constitutes a physician-conducted medication review is needed.

KEY WORDS: medication review; drug therapy management; pharmaceutical care; physician-patient communication; qualitative methods.

$\mathrm{J}$ Gen Intern Med 24(12):1296-302

DOI: $10.1007 / \mathrm{s} 11606-009-1132-4$

(c) Society of General Internal Medicine 2009

Received December 18, 2008

Revised May 27, 2009

Accepted September 14, 2009

Published online October 8, 2009

\section{INTRODUCTION}

Prescription medication use in the United States is increasing, with the average person filling over 12 pharmacy prescriptions per year in 2006. ${ }^{1}$ Older patients, who fill a mean of 30 prescriptions each year, ${ }^{2}$ are particularly susceptible to medication-related problems associated with polypharmacy and multiple prescribing physicians. ${ }^{3}$ In addition, older patients frequently take their medications differently from the way they are prescribed, often take medications of which their physicians are unaware, ${ }^{4-6}$ and are commonly nonadherent to their medication regimens. ${ }^{7}$ Some of these discrepancies arise due to confusion about how to take medications or are related to patient-experienced adverse effects. ${ }^{8}$ Because of this, it is important for clinicians to conduct medication reviews.

A medication review is a discussion of a patient's complete medication list. Studies have found that pharmacist-led medication reviews can correct some medication-related discrepancies, lower medication costs, and decrease the number of drugs prescribed. ${ }^{9-12}$ However, meta-analyses and systematic reviews have found no association between pharmacist-led medication reviews and lower hospital admission rates or mortality in older patients, ${ }^{10,13}$ perhaps because some patients prefer physician-led discussions. ${ }^{14}$ Physician-conducted medication reviews can result in more appropriate patient medication use, ${ }^{15}$ but clinical outcomes of reviews have not been studied.

Quality measures and guidelines recommend that physicians conduct medication reviews at least yearly with all older patients, ${ }^{16,17}$ but do not specify the content of these reviews or the manner in which they should occur. National quality and safety measures specify that medication reconciliation should occur after a hospitalization and across the continuum of care. ${ }^{18-20}$ These measures suggest that providers should obtain a list of all of a patient's medications, and also review the medication dose, frequency, route of administration, and indication for each medicine. ${ }^{19,21}$ The pharmacy literature describes different types of medication review: a prescription review to address technical issues related to prescriptions, a concordance and compliance review to address issues related to patient medication-taking behavior, and a clinical medication review that addresses medication issues in the context of a patient's clinical condition. ${ }^{22}$ Comprehensive medication reviews ${ }^{9,22,23}$ may require $30-45 \mathrm{~min}$ to complete, and are infeasible for physicians to perform in busy primary care settings.

Currently, there are no empirically based recommendations concerning how physicians should conduct medication 
reviews, and few studies have examined how physicians approach the content of a medication review. ${ }^{24,25}$ To complicate the issue, health care providers have mixed opinions about the purpose of a medication review, which may result in different ideas about what to do when conducting a review. Little is known about how physicians solicit information about chronic medications, what the discussions consist of, and how they are integrated into an office visit. An understanding of these strategies could lead to recommendations to optimize communication. The goal of this study was to describe how physicians conduct medication reviews when seeing older patients in the office setting.

\section{METHODS}

The investigators analyzed the Physician Patient Communication Project, a study conducted between January and November 1999 in two health care systems in Sacramento, California. Patients and physicians were surveyed prior to and immediately after office visits, and visits were audio-taped and transcribed. Full study details have been described. ${ }^{26}$ The study was approved by the UC-Davis and UCLA Institutional Review Boards.

\section{Physician and Patient Samples}

Physicians were recruited from the UC-Davis Medical Group and Kaiser Permanente. Eleven family physicians and 17 internists had patients included in this analysis. Research assistants randomly sampled physician appointment books prior to patient visits and telephoned patients aged 18 years or older. Eligible patients had to speak English and reported having a new or worsening medical problem, or being at least "somewhat concerned" about their health or about having a potentially serious undiagnosed condition.

Of the 4,560 patients selected for contact, 1,332 patients were eligible for the study, and 909 (68\%) were enrolled. Audiotapes for 632 visits were transcribed. We selected 122 visits in which patients aged 65 and older saw a primary care provider previously known to them, for either a follow-up visit (118 encounters) or a comprehensive physical examination (4 encounters). After reviewing the audiotapes and transcriptions, we dropped 7 visits where the tape ended prior to the end of the visit, 7 where the patient was asked to return to the office the same day after a diagnostic test, and 8 in which transcript review and physician report indicated that the patient was not taking any chronic medications, leaving a total of 100 visits containing potential medication review conversations.

\section{Patient and Physician Surveys}

Patients were asked about demographics, amount of time since they last saw any physician, and about their physical functioning at the time of the visit (36-item Short-Form Health Survey physical functioning scale, version 1, range from $0-100$, with 100 indicating maximum function; $\alpha=0.93^{27}$ ). Physicians were queried about their demographics and specialty, and were asked about the number of chronic medications continued for each patient. We used STATA statistical software, version 10.0 (StataCorp, College Station, TX) to tabulate descriptive statistics for patient, physician, visit and medication characteristics.

\section{Determination of Whether All Chronic Medications Were Mentioned During Visit}

To identify office visits in which each medication was mentioned, the investigators first reviewed audio tapes and transcripts to determine the number of chronic medications, vitamins, and herbal supplements that were mentioned by name, class, or purpose during the visit. Next, we compared the number of medications actually mentioned during the visit to the number of chronic patient medications physicians reported they had the patient continue on a post-visit questionnaire. If results from the transcript and survey differed, we used the larger number as the total number of chronic medications. If the number of medications discussed during the visit was equal to or greater than the number reported by the physician, or if the physician did not respond to the survey question (three visits), we gave credit for mentioning all patient medications during the visit.

\section{Qualitative Analysis: Approach, Topics, and Sequential Versus Non-Sequential Discussion}

The goals of this analysis were to explore how physicians approached chronic medication discussions during an office visit, to determine the topics discussed, and to assess the sequence in which medications were broached. To do so, the investigators examined conversations about all chronic prescription medications, vitamins and herbal supplements, overthe-counter (OTC) and pro re nata (PRN, as needed) medications that patients were taking at the time of the visit. Conversations about medications used for acute conditions, such as antibiotics and cough preparations, were not assessed, nor were new medication prescriptions, previously discontinued patient medications, or medications discussed but not prescribed.

We employed an iterative qualitative approach to transcript analysis using a form of qualitative content analysis, ${ }^{28,29}$ and analyzed transcripts inductively using the communication recorded in the transcripts to understand physician behavior patterns. ${ }^{29}$ The analysis was performed at both the visit and the medication level. Whether and how physicians introduced a medication review was explored. For each chronic medication or supplement mentioned during a visit, the topics brought up in the conversation concerning the medication were noted.

In addition, we investigated the sequence in which medications were mentioned during the visit. In "sequential" discussions, medications were mentioned in an uninterrupted fashion, without intervening non-medication discussion. Nonsequential medication references occurred when the medications were mentioned in the context of discussing other care (e.g., a recent hospitalization or side effect) or when a discussion focused on a single medication. An office visit was defined as containing a sequential discussion of medications if half or more of the medications discussed during the visit were considered in this manner. For patients taking only one prescription medication, a discussion was considered sequential if the patient was given the opportunity to list other medications or supplements, since this could lead to a sequential discussion of additional medications.

Four investigators participated in the qualitative analysis. Two of them (DMT, NSW) together identified recurring topics 
and developed a system to codify them. A preliminary codebook was established with topics, definitions, and examples of each code. A third investigator (SF) reviewed $25 \%$ of the transcripts to help refine the coding system and definitions and to ensure validity of the codes. Through this process, we merged and adjusted codes and revised the codebook accordingly. One of the investigators (DMT) reviewed and coded all of the transcripts using the final codes, and another (DAP) double-coded $25 \%$ of the transcripts, achieving a kappa coefficient with omission calculation of $0.86 .^{30}$ Disagreements were resolved by consensus among the four investigators.

\section{RESULTS}

The 100 patients in the study had a mean age of $73.6(\mathrm{SD}=5.9$, range 65-89). About half were female, most were Caucasian, and two-thirds had at least some college education. The mean number of chronic medications based on physician report was $3.6(\mathrm{SD}=2.8)$, and the mean number of prescription medications discussed during the visit was $2.6(\mathrm{SD}=2.1)$ (Table 1). Fifteen of the physicians practiced at Kaiser Permanente and 13 at UC-Davis Medical Group. Sixty-eight percent of physicians were male.

Based on transcripts and surveys, the 100 patients were taking 410 medications. In 54\% of visits, a patient's full set of medications was mentioned by name, class, or purpose. Of the 410 medications, there were 275 chronic prescription medications and 54 vitamins or over-the-counter medications. The other 81 medications cannot be characterized because they were not explicitly mentioned during the office visit.

\section{Qualitative Analysis}

The qualitative analysis revealed two major categories of discussion about chronic medications. One type of discussion

Table 1. Patient, Visit, and Medication Characteristics

\begin{tabular}{|c|c|c|c|}
\hline Characteristic & $\mathrm{n}^{*}$ & Percent & \\
\hline Female & 100 & 53 & \\
\hline Caucasian & 100 & 93 & \\
\hline Educational level & 99 & & \\
\hline High school or less & & 32 & \\
\hline Some college education & & 40 & \\
\hline College graduate & & 27 & \\
\hline $\begin{array}{l}\text { Greater than } 2 \text { months since last } \\
\text { visit with any medical doctor }\end{array}$ & 99 & 33 & \\
\hline Visit to a male physician & 100 & 80 & \\
\hline Visit to an internist & 100 & 64 & \\
\hline \multirow[t]{2}{*}{ UC-Davis patient } & 100 & 42 & \\
\hline & $\mathbf{n}^{*}$ & Mean (SD) & Range \\
\hline Age & 100 & $73.6(5.9)$ & $65-89$ \\
\hline Physical functioning at time of visit & 99 & $54.0(25.5)$ & $0-100$ \\
\hline No. of chronic meds taken by patient & 97 & $3.6(2.8)$ & $0-12$ \\
\hline $\begin{array}{l}\text { No. of prescription meds } \\
\text { discussed during visit }\end{array}$ & 100 & $2.6(2.1)$ & $0-8$ \\
\hline $\begin{array}{l}\text { No. of vitamins/supplements } \\
\text { discussed during visit }\end{array}$ & 100 & $0.6(1.3)$ & $0-7$ \\
\hline $\begin{array}{l}\text { No. of new medications } \\
\text { prescribed during visit }\end{array}$ & 100 & $0.5(0.6)$ & $0-3$ \\
\hline
\end{tabular}

*Variation in $n$ is due to missing observations relates to obtaining a complete list of patient medications. The second type of discussion is a set of specific topics related to managing chronic medications. Below we describe these two major categories. Then we consider the sequence in which medications are mentioned during visits.

Approach to Obtaining a Patient's Complete Medication List. The qualitative analysis identified four types of efforts to obtain a complete list of patient medications. At least one of these approaches was found in $36 \%$ of office visits. The approaches consist of: (1) discussion about a patient's medication bottles or a patient-generated list of medications, (2) broad questions assessing patient medications, (3) questions ensuring that a patient's entire medication list had been captured during the visit, and (4) explicit review (statements in which physicians stated their intention to go over all of a patient's medications). Table 2 contains examples describing each approach.

The following discussions illustrate examples of physicians' approaches to obtaining a patient's complete list of medications. Some physicians asked broad questions that elicited patient participation in listing their medications, for example:

Doctor: What medicines are you taking now?

Patient: Okay. I...now I know it is in here someplace.

Okay. I am taking Prilosec at $20 \mathrm{mg}$ one a day, which I

really depend on them things.

Doctor: Um hm.

Patient: And Lipitor, which is for the cholesterol, $20 \mathrm{mg}$, one a day. And indocin. Now, indocin I am taking about one every other day. That is for the gout.

When prompted for his medication list, this patient also provided additional information, such as the medication dose and frequency of intake, indicating familiarity with his medication regimen and the purpose of many of the medicines. In this example the physician asked a question requiring the patient to touch on each of her medications, but this did not always need to occur for a complete assessment of patient medications. For example, broad questions requiring only a limited patient response also could give complete information about medications taken:

Doctor: So you're not taking anything now?

Patient: That's right, only the cholesterol, that's all.

Doctor: Gotcha.

Below is an example of a physician ensuring that a patient's complete medication list was captured during the visit. This physician verified an 82-year-old patient's medication list with his daughter by naming the medications and asking for her agreement about the drugs mentioned:

Doctor: So Lasix, Diovan, Imdur, Cardura. I have Elavil down. Are you still taking that at bedtime?

Daughter: Uh huh.

Doctor: Okay. So that is five.

Daughter: And Cardizem.

Doctor: Cardizem is six. Potassium is seven. Coumadin

is eight. Are you taking Zantac as well? 
Table 2. Frequency of Discussion and Examples of Approaches to Obtaining a Patient's Complete Medication List and Topics Related to Management of Chronic Medications

\begin{tabular}{|c|c|c|c|}
\hline \multicolumn{4}{|c|}{ Approach to obtaining a patient's complete medication list" } \\
\hline & \multicolumn{2}{|l|}{$\begin{array}{l}\text { Percent of encounters } \\
(n=100)\end{array}$} & Example \\
\hline $\begin{array}{l}\text { Medication list/bottles } \\
\text { Patient brought medication } \\
\text { bottles/list to visit }\end{array}$ & \multicolumn{2}{|l|}{14} & "I got these medicines here" \\
\hline Broad question & \multirow{2}{*}{\multicolumn{2}{|c|}{11}} & "What medicines are you taking now?" \\
\hline $\begin{array}{l}\text { Physician asked broad question } \\
\text { assessing medications }\end{array}$ & & & $\begin{array}{l}\text { "You are on basically two medicines?" } \\
\text { "Have you started any new medicines lately?" }\end{array}$ \\
\hline $\begin{array}{l}\text { Ensure capture } \\
\text { Physician ensured all medications } \\
\text { captured }\end{array}$ & \multicolumn{2}{|l|}{9} & "What else are you taking?" \\
\hline $\begin{array}{l}\text { Explicit review } \\
\text { Physician stated intention to go } \\
\text { over all medications }\end{array}$ & \multicolumn{2}{|l|}{7} & "Let's review your medicines right now" \\
\hline \multicolumn{4}{|c|}{ Topics related to management of chronic medications } \\
\hline & $\begin{array}{l}\text { Percent of encounters } \\
(\mathbf{n}=100)\end{array}$ & $\begin{array}{l}\text { Percent of medications } \\
(n=410)\end{array}$ & Example \\
\hline Efficacy & 66 & 31 & $\begin{array}{l}\text { "...the Tagament seems to be working fine" } \\
\text { "Does that help when you take it?" } \\
\text { "Well, your blood pressure looks really good" }\end{array}$ \\
\hline Medication directions & 59 & 27 & $\begin{array}{l}\text { "You take it three times a day?" } \\
\text { "You only take two at night" }\end{array}$ \\
\hline Side effects & 37 & 13 & $\begin{array}{l}\text { "You see, the blood pressure pill expands my ankles" } \\
\text { "Do you think the Cardizem gives you any side effects? } \\
\text { Does it bother you any?" } \\
\text { "I think part of that is the trazodone. Dry mouth" }\end{array}$ \\
\hline Adherence & 35 & 13 & $\begin{array}{l}\text { “...I haven't been taking my pills" } \\
\text { "It doesn't look in the last year like you have gotten } \\
\text { anything filled for cholesterol" } \\
\text { "And you should make sure you take that Fosamax } \\
\text { every day..." }\end{array}$ \\
\hline Monitoring & 33 & 12 & "Well, we need to check your potassium again" \\
\hline Medication supply/refills & 32 & 20 & $\begin{array}{l}\text { "Oh I do need a prescription, before I forget, } 90 \text { days } \\
\text { of the Pravachol, } 40 \mathrm{mg} \text { " } \\
\text { "Do you need any refills on anything?" }\end{array}$ \\
\hline Medication changed/adjusted & 32 & 9 & $\begin{array}{l}\text { "So, stop the Nitro-Bid and a couple of days later } \\
\text { stop the atenolol and see how you do" }\end{array}$ \\
\hline Patient told to continue meds & 32 & 17 & "Keep all the same medicines going, okay?" \\
\hline Medication dose & 30 & 10 & $\begin{array}{l}\text { "That was the } 1 \mathrm{mg} \text {, right?" } \\
\text { "And the Lotensin } 10 \mathrm{mg} "\end{array}$ \\
\hline $\begin{array}{l}\text { Medication cost/insurance } \\
\text { issues }\end{array}$ & 12 & 4 & $\begin{array}{l}\text { MD: "The Xanax is no longer formulary" } \\
\text { Pat: "That doesn't cost much, but the others are high" }\end{array}$ \\
\hline
\end{tabular}

"One or more of these topics were addressed in 36 of 100 encounters

Daughter: Yes, he is.

Doctor: Nine. That sounds about right. Nine pills?

Daughter: Yeah.

Though the patient's daughter contributed to the conversation by telling the physician about the Cardizem, this type of query requires little from the patient outside of tacit agreement.

Another physician, who reported on the physician survey that his 75-year-old patient was taking five medications, asked a broad question about whether the patient's medication list had recently changed, and followed the question with an explicit review statement concerning his plans to review the patient's medications: Doctor: "Have you started any new medicines lately?" Patient: "Nope." Doctor: "Because I was going to review them." Patient: "Same thing. The only one I don't take anymore was that capsule, oh I can't think of the name now...it's brown pills." These types of statements can set the stage for a complete discussion of a patient's medications.

Topics Related to Management of Chronic Medications. We identified ten topics of discussion about specific chronic medications related to medication management (Table 2): (1) medication efficacy, (2) directions for use, (3) potential side effects or adverse events, (4) medication adherence, (5) laboratory or other monitoring of medications, (6) medication supply or refills, (7) directions for changing or adjusting chronic medications, (8) directions for continuing chronic medications, (9) medication dose, and (10) medication cost or insurance issues.

Frequency of discussion about each of the topics ranged from $12 \%$ of encounters for cost issues to $66 \%$ for efficacy discussion. In other words, specific medications were most often discussed in terms of their effect on symptoms or a disease process. Medication directions were commonly noted 
(59\% of encounters), but were discussed for all of a patient's chronic medications during only eight visits (8\%).

Few medication management topics were routinely discussed during office visits. The mean number of topics (of the 10) discussed during the 100 visits was $3.7(\mathrm{SD}=2.5)$, with a range from 0 to 10 . In $13 \%$ of visits, no medication management topic was discussed, and all ten topics were discussed during only one visit (Fig. 1). One or more medication management topics were discussed for each of a patient's chronic medications in $47 \%$ of visits.

Each of the ten medication management topics was discussed for less than one-third of the 410 medications taken by the patients in the study (Table 2, column 3). The mean number of topics discussed for each of the 410 medications was $1.5(\mathrm{SD}=1.7)$, with a range of 0 to 7 . Prevalence of specific discussion topics ranged from $4 \%$ (cost) to $31 \%$ (efficacy) (Table 2). Forty-two percent of chronic medications had no medication management topics discussed, $45 \%$ had between one and three topics discussed, and 13\% had four or more topics discussed (Fig. 1).

Patients contributed to the content of the medication discussions by asking questions or making comments. Patients brought up medication adherence (particularly problems with adherence) during $25 \%$ of the encounters, while physicians initiated adherence discussions for $10 \%$. Similarly, patients brought up medication refills or commented about their supply of medications more frequently (21\% of visits) than physicians (15\% of visits).

Sequential Versus Non-Sequential Discussion. Discussion of patient medications was not always delimited to a single conversation. Most frequently medications were mentioned in a combination of sequential and sporadic discussions interspersed throughout the office visit. In 45 of the 100 visits, the majority of the patient's medications discussed during the visit were reviewed as a sequential discussion in which medications were mentioned or discussed without

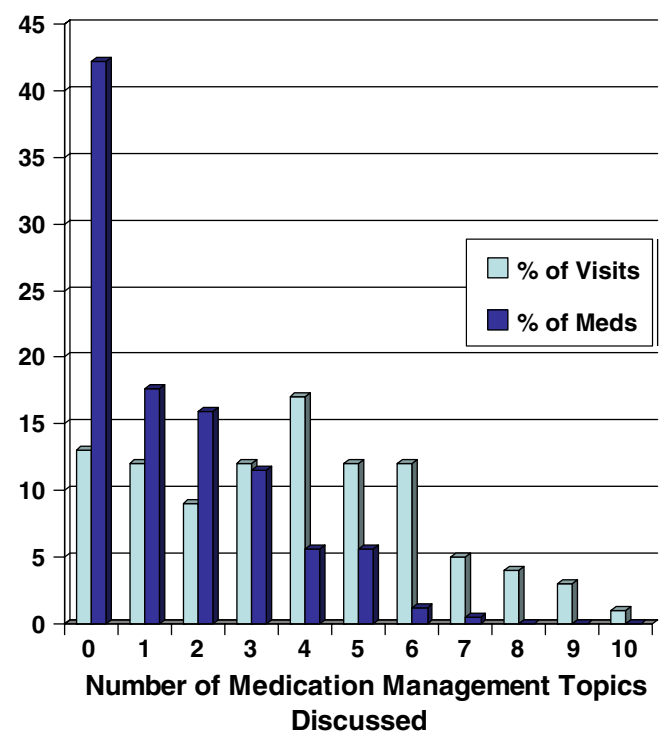

Figure 1. Percentage of visits and medications for which topics related to medication management were discussed. intervening conversation. Medications were more likely to be mentioned sequentially when physicians made efforts to obtain a complete list of patient medications (29 of 36 visits; $81 \%$ ), compared to visits in which no efforts were made (16 of 64 visits; 25\%).

Visits in which all of a patient's medications were explicitly mentioned by name, medication class, or purpose were more likely to contain sequential discussion of chronic medications than those in which not all of a patient's medications were named. Among the 54 visits in which all medications were specifically named, the majority of medications were brought up sequentially in 32 (59\%) visits. In these visits, 167 medications were mentioned (mean 3.1/visit). In contrast, in the 46 visits in which not all of the chronic medications were specifically named, the medications were mentioned sequentially in 13 (28\%) visits. Only 93 of 243 medications (mean 2.0/ visit) were brought up during these visits with non-sequential discussions.

\section{Overall Physician Approach to Medication Review}

Merging the quantitative with the qualitative findings, in 67 of the 100 office visits, either each of a patient's medications was touched on or the physician attempted to obtain a complete medication list (but did not specifically name each medication). Of these 67 visits, sequential discussions occurred in 41 visits (61\%): 32 in which all medications were specifically named, and 9 in which there was an effort to obtain the patient's complete medication list (but not all medications were specifically mentioned). Of these 41 visits, there were 28 in which at least one medication management topic was raised for each of the patient's medications. As a result, a systematic discussion that touched on at least one topic for each medication the patient was taking occurred in only $28 \%$ of visits.

\section{DISCUSSION}

For countless years, physicians have performed the fundamental tasks associated with medication review on a daily basis. Guidelines and quality measures have now canonized these tasks as required elements of care. This study teases out what physicians discuss during office visits about a patient's medication regimen and shows that most physicians do not come close to conducting all elements of a medication review.

Comprehensive evaluation of chronic medications was rare in the visits studied. Specific details about a medication were discussed for just over half of the medications the patients were taking, and none of the 100 continuity office visits in this study included a comprehensive consideration of dosing, adherence, efficacy, and side effects.

This analysis identified three distinct aspects of the way that physicians operationalize medication review during office visits: efforts aimed at obtaining a patient's complete medication list, discussion of topics about medication management, and sequential versus non-sequential discussion of medications. These topics are similar to those included in detailed pharmacist medication reviews, ${ }^{9,22,23}$ but are targeted in clinically relevant ways and often to particular medications or clinical issues. The elements of physician-conducted medication review identified in this study may constitute an empiri- 
cally derived basis for a definition of physician medication review.

Physicians endeavored to conduct a comprehensive accounting of a patient's medications in several ways. Some were time-consuming, such as when physicians queried patients about each of their medications in a systematic fashion. However, this style may lead to recognition of discrepancies between what a patient is taking and what the physician believes the patient is taking. Others, such as asking if any medications have changed without specifically touching on each individual medication, could serve to verify a medication list, but required less participation from the patient. In a setting in which a patient may have frequent office visits or in which electronic medical records are accurately maintained, asking about changes may afford an efficient mechanism for medication review.

Due to time constraints during office visits, comprehensive medication review may best be performed by a non-physician health care provider, such as a nurse or pharmacist. While pharmacist-led medication-related interventions can improve patient health outcomes, ${ }^{31,32}$ pharmacist medication reviews in older patients have met with less success. ${ }^{10,13}$ Pharmacist reviews may be limited because they are not directly linked to changes in clinical care, and physicians do not always implement pharmacists' suggestions. ${ }^{33,34}$ Older patients may be reticent to accept pharmacist suggestions ${ }^{35,36}$ and may prefer to have their medications reviewed by their physician. ${ }^{14}$ Although not a panacea, ${ }^{37,38}$ medication reconciliation features incorporated into many electronic health record systems may allow physicians to implement medication review more easily.

This study is limited by the nature of the office visits captured. Few visits were comprehensive examinations, which we hypothesize would be more likely to contain a medication review. Physicians may not regularly perform medication reviews during follow-up visits, and patients may have had another visit during the year in which their physician performed a medication review. Physicians who have a reliable nurse or medical assistant collecting information about patient medication regimens may not repeat the process. We do not know whether this occurred prior to the physician-patient encounter.

This study was also limited because we did not have access to patient medical records, and instead relied on physician reports in determining the total number of patient medications. When the number of medications touched upon during the visit exceeded the physician's reported number, we considered the larger number of medications to reflect the regimen. This may have resulted in an overestimate of physician completeness, but does not affect the description of the topics addressed. Furthermore, we did not require dietary supplements, over-the-counter, or as needed (PRN) medications to be assessed, and have no relevant outcome data to assess the effect of the medication reviews performed. Other limitations include the potential effect of having a tape recorder in the room, which may alter physician and patient behavior. If anything, the Hawthorne effect may have enhanced physician communication about medications. The patients in this study were mostly white and well-educated, and most visited a male physician. In addition, the study focused on older patients in a single city.
It is increasingly recognized that medication review is a critical aspect of the clinical encounter. A practical definition of medication review is needed to monitor performance and guide interventions. While medication review likely will become more efficient as physicians adopt electronic medical record systems, this study illustrates that, at least among the physicians studied, medication review is not carried out and needs substantial improvement.

Acknowledgments: The authors would like to thank William $H$. Shrank, assistant professor in the Division of Pharmacoepidemiology and Pharmacoeconomics, Department of Medicine, at Brigham and Women's Hospital/Harvard Medical School in Boston, Massachusetts, for his contributions to the manuscript. Data used in this study were collected with support from the Robert Wood Johnson Foundation (grant no. 034384). Dr. Tarn was supported by a UCLA Mentored Clinical Scientist Development Award (5K12AG001004) and by the UCLA Older Americans Independence Center, NIH/NIA grant P30-AG028748. Dr. Kravitz was supported in part by a midcareer research and mentoring award from the National Institute of Mental Health (1K24MH072756-01). The manuscript content does not necessarily represent the official views of the National Institute on Aging or the National Institutes of Health.

Conflict of Interest: None disclosed.

Corresponding Author: Derjung M. Tarn, MD, PhD; Department of Family Medicine, David Geffen School of Medicine, University of California-Los Angeles, 10880 Wilshire Blvd., Suite 1800, Los Angeles, CA 90024, USA (e-mail: dtarn@mednet.ucla.edu).

\section{REFERENCES}

1. Prescription Drug Trends Fact Sheet: May 2007 Update: Kaiser Family Foundation; 2007.

2. Cost Overdose: Growth in Drug Spending for the Elderly, 199220132010. Publication No. 00-107. Washington, DC: Families USA Foundation; 2000.

3. Barry PJ, Gallagher $\mathbf{P}$, Ryan C. Inappropriate prescribing in geriatric patients. Curr Psychiatry Rep. 2008;10:37-43.

4. Bedell SE, Jabbour S, Goldberg R, et al. Discrepancies in the use of medications: their extent and predictors in an outpatient practice. Arch Intern Med. 2000;160:2129-34.

5. Bikowski RM, Ripsin CM, Lorraine VL. Physician-patient congruence regarding medication regimens. J Am Geriatr Soc. 2001;49:1353-7.

6. Ostrom JR, Hammarlund ER, Christensen DB, Plein JB, Kethley AJ. Medication usage in an elderly population. Med Care. 1985;23:157-64.

7. Safran DG, Neuman P, Schoen C, et al. Prescription drug coverage and seniors: findings from a 2003 national survey. Health Aff (Millwood) 2005; Suppl Web Exclusives:W5-152-W5-66.

8. Kairuz T, Bye L, Birdsall R, et al. Identifying compliance issues with prescription medicines among older people: a pilot study. Drugs Aging. 2008;25:153-62.

9. Zermansky AG, Petty DR, Raynor DK, Freemantle N, Vail A, Lowe CJ. Randomised controlled trial of clinical medication review by a pharmacist of elderly patients receiving repeat prescriptions in general practice. BMJ. 2001;323:1340-3.

10. Holland R, Desborough J, Goodyer L, Hall S, Wright D, Loke YK. Does pharmacist-led medication review help to reduce hospital admissions and deaths in older people? A systematic review and meta-analysis. $\mathrm{Br} \mathrm{J}$ Clin Pharmacol. 2008;65:303-16.

11. Read H, Ladds S, Rhodes B, Brown D, Portlock J. The impact of a supplementary medication review and counselling service within the oncology outpatient setting. Br J Cancer. 2007;96:744-51.

12. Farris KB, Ganther-Urmie JM, Fang G, et al. Population-based medication reviews: a descriptive analysis of the medication issues identified in a Medicare not-for-profit prescription discount program. Ann Pharmacother. 2004;38:1823-9. 
13. Royal S, Smeaton L, Avery AJ, Hurwitz B, Sheikh A. Interventions in primary care to reduce medication related adverse events and hospital admissions: systematic review and meta-analysis. Qual Saf Health Care. 2006; 15:23-31.

14. Jones $\mathbf{D}$, Seymour $\mathbf{R}$, Woodhouse $\mathbf{K}$. Use of pharmacists by older people in the community. Arch Gerontol Geriatr. 1997;24:9-13.

15. Pit SW, Byles JE, Henry DA, Holt L, Hansen V, Bowman DA. A Quality Use of Medicines program for general practitioners and older people: a cluster randomised controlled trial. MJA. 2007;187:23-30.

16. Shrank WH, Polinski JM, Avorn J. Quality indicators for medication use in vulnerable elders. J Am Geriatr Soc. 2007;55(Suppl 2):S373-82.

17. Medicines and older people: implementing medicines related aspects of the National Service Framework for Older People. London: DoH: Department of Health; 2001

18. The Joint Commission on Accreditation of Healthcare Organizations. 2009 National Patient Safety Goals. Available at http://www jointcommission.org/PatientSafety/NationalPatientSafetyGoals /. Accessed August 27, 2009.

19. American Geriatrics Society/Physician Consortium for Performance Improvement/National Committee for Quality Assurance. Geriatrics Physician Performance Measurement Set. August 2007. Available at http://www.ama-assn.org/ama / pub/upload/mm/370/geriatricsws 061308.pdf. Accessed August 27, 2009.

20. American Medical Association and National Committee for Quality Assurance. Geriatric Care: Medication Reconciliation. 2004 - 2006 Available at http://www.aan.com/globals/axon/assets/3436.pdf. Accessed August 27, 2009.

21. The Joint Commission on Accreditation of Healthcare Organizations. FAQs for the 2008 National Patient Safety Goals. March 2008. Available at http://www.jointcommission.org/NR/rdonlyres/ F770FD7F-C0F2-4454-B4F8-C8D38D4559BB/0/2008_FAQs_NPSG 08.pdf. Accessed August 27, 2009.

22. Clyne W, Blenkinsopp A, Seal R. A Guide to Medication Review 2008: Medicines Partnership Programme. Available at: http://www.keele.ac.uk/ schools/pharm/npcplus/medpartpubs.htm; Accessed on August 27, 2009

23. Lowe CJ, Petty DR, Zermansky AG, Raynor DK. Development of a method for clinical medication review by a pharmacist in general practice. Pharm World Sci. 2000;22:121-6.

24. Bokhour BG, Berlowitz DR, Long JA, Kressin NR. How do providers assess antihypertensive medication adherence in medical encounters? J Gen Intern Med. 2006;21:577-83.
25. Pit SW, Byles JE, Cockburn J. Medication review: patient selection and general practitioner's report of drug-related problems and actions taken in elderly Australians. J Am Geriatr Soc. 2007;55:927-34.

26. Kravitz RL, Bell RA, Azari R, Krupat E, Kelly-Reif S, Thom D. Request fulfillment in office practice: antecedents and relationship to outcomes. Med Care. 2002;40:38-51.

27. Ware J. SF-36 health survey. In: The use of psychological testing for treatment planning and outcomes assessment, 2nd edn. Mahwah, NJ: Lawrence Album; 1999:1227-46.

28. Miles M, Huberman A. Qualitative data analysis: an expanded sourcebook. 2nd ed. Thousand Oaks, CA: Sage Publications; 1994.

29. Denzin NK, Lincoln YS. Handbook of qualitative research. 2nd ed. Thousand Oaks, Calif.: Sage Publications; 2000.

30. Simon P. Including omission mistakes in the calculation of Cohen's kappa and an analysis of the coefficient's paradox features. Educ and Psych Meas. 2006;66:765-77

31. Wu JY, Leung WY, Chang S, et al. Effectiveness of telephone counselling by a pharmacist in reducing mortality in patients receiving polyphar macy: randomised controlled trial. BMJ. 2006;333:522

32. Green BB, Cook AJ, Ralston JD, et al. Effectiveness of home blood pressure monitoring, Web communication, and pharmacist care on hypertension control: a randomized controlled trial. JAMA. 2008;299: 2857-67.

33. Chen TF, de Almeida Neto AC. Exploring elements of interprofessional collaboration between pharmacists and physicians in medication review. Pharm World Sci. 2007;29:574-6.

34. Mannheimer B, Ulfvarson J, Eklof S, et al. Drug-related problems and pharmacotherapeutic advisory intervention at a medicine clinic. Eur $J$ Clin Pharmacol. 2006;62:1075-81.

35. Salter C, Holland R, Harvey I, Henwood K. "I haven't even phoned my doctor yet." The advice giving role of the pharmacist during consultations for medication review with patients aged 80 or more: qualitative discourse analysis. BMJ. 2007;334:1101.

36. Petty DR, Knapp P, Raynor DK, House AO. Patients' views of a pharmacist-run medication review clinic in general practice. $\mathrm{Br} \mathrm{J}$ Gen Pract. 2003;53:607-13.

37. Orrico K. Sources and types of discrepancies between electronic medica records and actual outpatient medication use. J Manag Care Pharm. 2008; 14:626-31.

38. Kaboli P, McClimon B, Hoth A, Barnett M. Assessing the accuracy of computerized medication histories. Am J Man Care. 2004;10:872-77. 